\title{
Discourse Competence Development in English as Second Language Learners: Effect of Poems on Proficiency and Performance
}

* Dr. Shaukat Ali, Assistant Professor (Corresponding Author)

** Mr. Saddam Hussain, Lecturer

*** Mr. Iftekhar Ali, MPhil Scholar

\begin{abstract}
This study investigates the effect of poems as language teaching materials on the discourse competence of English as a second language learners (ESL) learners. Discourse competence is one of the sub-skills of English speaking skills which has further been divided into two sub-skills called 1) organizing a coherent conversation and 2) then maintaining it. It was a quasi-experimental study consisting of a control group (CG) and an experimental group (EG) from the faculty of social sciences, University of Malakand, Pakistan. They were the students of the third semester and were taught English as a minor course. Before the commencement of the experiment, the students of both groups were subjected to a speaking type pre-test. Immediately after the pre-test, the control group was taught through traditional teaching materials whereas; the treatment group was treated with poems as teaching materials. Moreover, observation field notes were employed to find out the reasons behind the performance of the students of both groups. After a six-week experiment, a post-test similar in nature to the pre-test was dispensed among the groups. The scores of the respondents of both groups were compared by using independent samples $t$-tests. The outcomes indicated that the learners in the treatment group scored significantly higher on the post-test than the learners in the comparison group. The observation field notes further displayed that the students of the treatment group were actively involved in the language learning process. Moreover, they associated the text of poetry with their, socio-cultural, and personal lives. Additionally, they enjoyed greater autonomy due to ambiguity and universality in the texts of the poems. The study suggests that poems should be utilized as teaching materials in ESL classrooms.
\end{abstract}

Keywords: Discourse Competence, Traditional Language Teaching Materials, Poems, Proficiency, Performance

\section{Introduction}

Language teaching materials enhance the motivation level of the language learners and provide learners with an opportunity to freely interact with one another. This practice increases the confidence level of language learners. Additionally, language teaching materials should have linguistic and cultural richness (Maley and Duff 1989). Furthermore, the relevance of the text to the personal and social lives of the learners enables the learners to construct meanings on their own. However, language teaching materials used in Pakistani university language classrooms are often based on grammar and language structure. Moreover, English is taught as a subject, not as a language. The focus is more often on teaching rules of the language. Besides, sentences are taught as isolated units, not as part of a connected discourse (Shamim 2008). As such, the emphasis is on the development of writing skills. Listening and reading skills are comparatively given less attention whereas, speaking skill is almost ignored. This research, therefore, endeavors to compare the outcome of conventional/traditional language teaching materials and the text of poetry on the discourse competence of ESL learners. Discourse competence comprises two sub-components namely organizing a coherent conversation and then maintaining the conversation (Louwerse and Mitchel 2003). The term conventional language teaching materials means all those language course books and other language teaching materials, which do not use literature as language teaching materials (Ghosn

\footnotetext{
* Department of English, University of Malakand, Pakistan. Email: shaukat1443all@gmail.com

** Department of English, University of Malakand, Pakistan. Email: sadam.khan10022@gmail.com

*** Qurtuba University of Science \& Information Technology, Peshawar, Pakistan.

Email: khan034319@gmail.com
} 
2002). However, this study uses the term "traditional teaching materials" for the language teaching materials which have been in use in the University of Malakand (UOM), Khyber Pakhtunkhwa (KP), Pakistan, since its inception to teach English language skills to the students not majoring in English. For this purpose, the researcher has developed a language teaching model called Poetry Guided Speaking (PGS). For this purpose, the researcher has developed a language teaching model called Poetry Guided Speaking (PGS). This model exploits poetry as language teaching materials.

\section{Literature Review}

Discourse Competence means organizing a coherent discourse so that the listeners do not miss any link to the message. This needs enough knowledge of interactional and information routines. It also means an appropriate use of grammatical and lexical reference to the people, things, and events, so that listeners are not confused as to who or what is being referred to during the conversation (Louwerse \& Mitchel, 2003). Discourse competence also refers to the use of discourse markers, which are of two types; conversational markers and informational markers. Conversational markers are used for maintaining the conversation or speech act. This includes, well, now, anyways, ok, and so on. Informational markers, on the other hand, are used for the initiation of conversation about a topic, changing the topic, handling the topic over to others, and relinquishing the topic. They consist of inter-sentential connectors like markers which show the causal associations, conceding connotations, and so on (Young, 2002). This speaking sub-skill also implies maintaining the conversation which demands making the conversation interesting and meaningful. Besides, the listeners should be active ones and should politely disagree or counter-argue (Yoshida, 2003). Additionally, it also calls for the ability how to manage the turn-taking, maintain it, and hand it over to others (House, 1996).

As mentioned in the preceding paragraph, discourse competence is about initiating a coherent conversation/discourse and then maintaining it. Language learners need such language teaching materials that could provide them with opportunities for free and frequent interaction with one another. Moreover, teaching materials should be open to role-plays and group activities. Furthermore, the text of teaching materials should appeal to the feelings and emotions of the learners(Khatib \& Rahimi, 2012). Besides, language teaching materials shall have elements of rudiments of the target language and its culture (Van, 2009). Besides, the language of teaching materials should be authentic and should have an association with the practical lives of learners (Ali, Gul \& Amin 2020). Regarding this, poetry could be exploited in an ESL classroom due to some of its characteristics. Poetry has relevance to the personal lives of learners. Its text is culturally and linguistically rich. Moreover, poetry deals with the fundamental human emotions which are common among all humans. Additionally, the text of poetry could be subjected to different interpretations which encourages language learners to freely interact in the target language (Maley \& Duff 1989; Carter \& Long 1991; Nasr 2001; Khatib \& Rahimi 2012). However, there has been little research on teaching discourse competence through the text of poetry in the higher learning institutions of Pakistan.

Thus, this study exploited the text of poetry as language teaching materials for developing the discourse competence of ESL learners.

\section{Poetry Guide Speaking (PGS)}

ESL learners in the universities of Pakistan are taught through either text of grammar or texts of phonetics and phonology or texts having both grammar and dialogues. These texts are mainly focused on developing learners' writing skills. Sentences and certain expressions are taught in isolation. Moreover, the rules of English are emphasized. Consequently, language learners develop an insight into the rules and could produce isolated sentences (Shamim, 2011). However, listening and reading skills are paid comparatively less attention whereas, speaking skill is almost overlooked. As a result, Pakistani graduates face problems in speaking the English language (Raza, 2008). Several reasons are enumerated for the poor speaking skill of Pakistani graduates. In respect of teaching materials, it is argued that the texts mentioned above could hardly be utilized for group activities inside the classroom. Moreover, the objective nature of these texts makes the learners hesitant to readily respond to questions. Additionally, these texts do not make sufficient appeal to the feelings and emotions of the learners.

Hence, as mentioned in Section 1.2, this study utilized poems as language teaching materials to teach how to 1) initiate a coherent conversation and 2) how to keep the conversation going. This researcher has developed a language teaching model called Poetry Guided Speaking (PGS). This model implies poems as teaching materials emphasizing especially on its cultural richness, linguistic 
richness, personal relevance, ambiguity, and universality. Furthermore, the model uses Communicative Language Teaching (CLT) as the chief teaching methodology supported by O'Brien's (1999) six stages of language teaching comprising; a) Preparation and anticipation, b) Focusing, c) Preliminary response, d) Working on text (level I), e) Working on text (level II), and f) Interpretation and personal response. The model is shown in Figure 1.1 as given below.

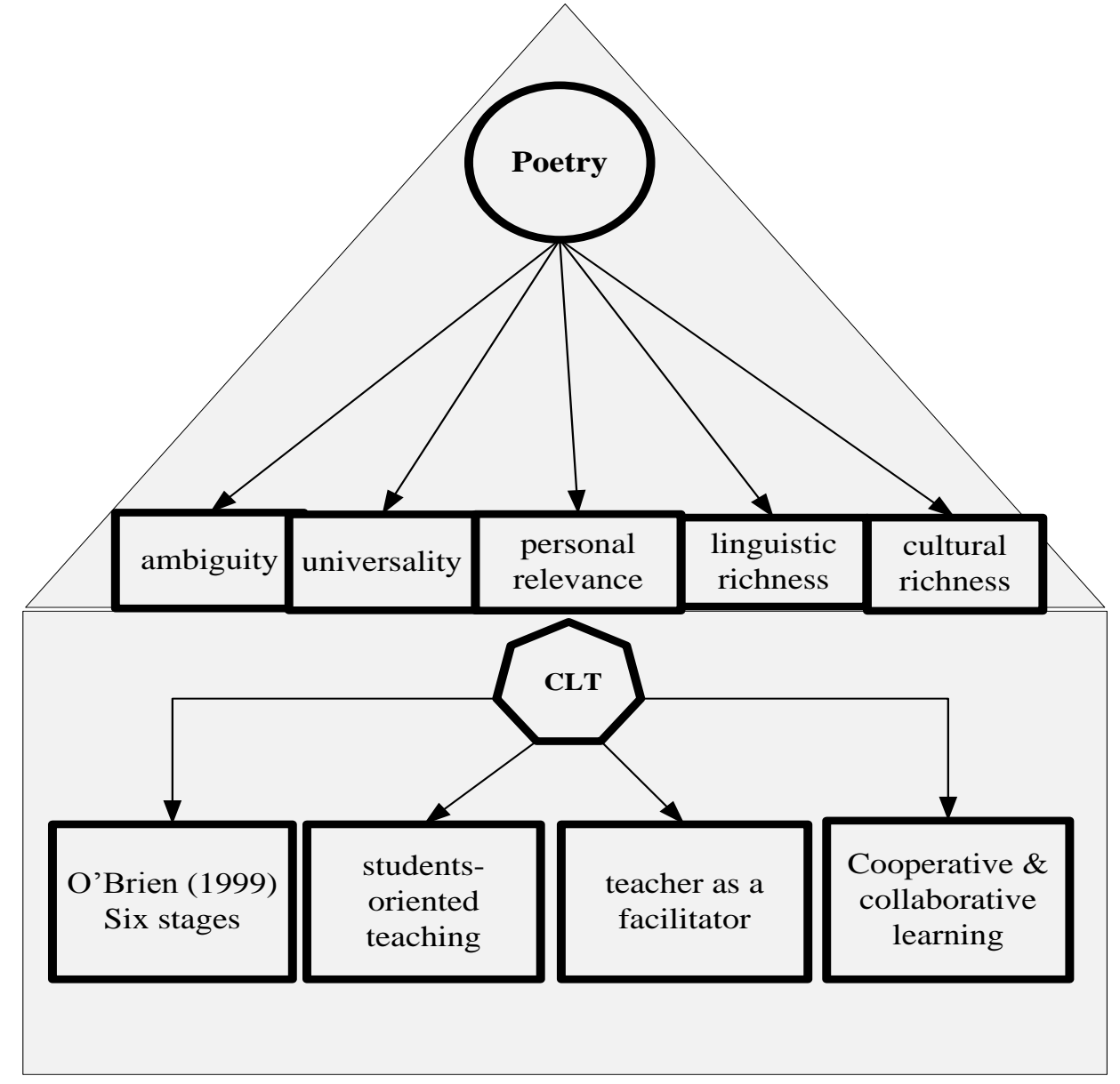

Figure 1.1 Poetry Guided Speaking (PGS)

Hence, this research study utilized poems as language teaching materials through PGS for teaching discourse competence to ESL learners in comparison to traditional language teaching materials. Contingent upon the previous relevant studies, this research work has the following set of hypotheses.

$\mathrm{HI}_{1}$. The text of poetry has a significant effect on the overall discourse competence of ESL learners.

$\mathrm{H}_{1}$. The text of poetry has no significant effect on the overall discourse competence of ESL learners.

$\mathrm{HI}_{2}$. The text of poetry has a significant effect on the sub-skills of discourse competence including 1) organizing a coherent conversation and 2) maintaining a conversation.

$\mathrm{HO}_{2}$. The text of poetry has no significant effect on the sub-skills of discourse competence including 1) organizing a coherent conversation and 2) maintaining a conversation.

Moreover, the study has the following objectives to accomplish.

i. To find out if the overall discourse competence of the students is developed through the text of poetry.

ii. To examine whether each sub-skill of the grammatical competence including 1) organizing a coherent conversation and 2) maintaining a conversation is improved while using the text of poetry. 


\section{Methodology}

This was quasi-experimental research comprising two integral groups; a comparison group and a treatment group. There were 35 students in each group, hence 70 students in all as indicated in the following table.

Table: 3.1 Number of Students in CG and EG

\begin{tabular}{lll}
\hline Control Group (CG) & No of Students & 35 \\
\hline Experimental Group (EG) & No of Students & 35 \\
Total No of Students & 70 & \\
\hline
\end{tabular}

Besides, the students of both groups were from the faculty of social sciences, who took English as a minor course. The students of the control group were taught through traditional teaching materials including High School Grammar and Grammar in Use whereas the students of the experimental group were treated with four poems as teaching materials. The pomes included The Rose Family by Robert Frost, Housekeeping by Natasha Tretheway, Church by Jacqueline Woodson, and September Tomatoes by Karina Borowicz. The poems were exploited through the PGS model. A speaking type pre-test was dispensed to both the groups before the experiment. Pre-test ensures the credibility of the results as compared to the studies relying on post-test only as pre-test determines the baseline of both the control and experimental groups (Dimitrov and Rumrill Jr 2003). After the pretest, a six-week-long experiment was conducted as mentioned above. At the end of the intervention, both the EG and CG were given a post-test. The results of the learners of CG and EG were then subjected to SPSS for analysis.

\section{Results of the Study}

Table 4.1 T-test Results of the Pre-test Comparing the CG and EG Mean Scores in Overall Discourse Competence (DC)

\begin{tabular}{|c|c|c|c|c|c|c|}
\hline Groups & $\mathrm{N}$ & $\mathrm{M}$ & SD & ST.Error M & T-value & P-Value \\
\hline Control & 35 & 23.5395 & 2.43397 & .39487 & \multirow{2}{*}{2.882} & \multirow{2}{*}{.004} \\
\hline Experimental & 35 & 21.9744 & 2.331002 & .37329 & & \\
\hline
\end{tabular}

Note: $p$-value $<0.05=$ significant, $p$-value $>.05=$ not significant

The $\mathrm{p}$-value in the table above stands for the level of significance, indicating the variance in the mean scores of the students of the groups. Moreover, a p-value higher than 0.05 displays that the variance in the mean scores of the learners of the aforementioned groups is insignificant whereas a pvalue of 0.05 or less than this indicates that the variance in the mean scores of the learners of the groups is significant. Thus, Table 4.1 above implies that there was a significant level of variance at the p-value 0.05 in overall discourse competence of comparison and treatment groups on the pre-test. However, the mean scores of the two groups confirm that the difference (with the p-value. 004) (see Table 1.2 above) in the overall discourse competence was significant in favor of the control group at 0.05. There could be several reasons for the enhanced proficiency of the control group than the experimental group on the pre-test. But when the researcher asked separately the students of both the groups about their respective English course teachers in the first semester, the learners of CG replied that their teacher of the English course in the first semester was hardworking, competent and encouraged them to speak English inside the classroom, whereas, the learners of EG were complaining against their teacher of the English course in the first semester. They said that their teacher was passive, boring, and did not use the English language frequently in the classroom. They added that he kept on switching over to the local language when explaining some difficult points. Hence, teaching methodology and incompetence of teachers could be some of the reasons for poor discourse competence of the students. However, the concern of this research endeavor is to ascertain the effectiveness of the prevailing language text for teaching discourse competence in comparison to poetry as teaching materials. It is, therefore, that this study has made the variable of the teacher constant in both the groups. The researcher, as a teacher, taught both the groups himself.

\begin{tabular}{|c|c|c|c|c|c|c|c|}
\hline $\begin{array}{l}\text { Sub-skills } \\
\text { of DC }\end{array}$ & Groups & $\mathrm{N}$ & $\mathrm{M}$ & SD & ST.Error. M & T-Value & P-Value \\
\hline $\mathrm{OC}$ & $\begin{array}{l}\text { CG } \\
\text { EG }\end{array}$ & $\begin{array}{l}35 \\
35\end{array}$ & $\begin{array}{l}3.1976 \\
3.2181\end{array}$ & $\begin{array}{l}.45827 \\
.41033\end{array}$ & $\begin{array}{l}.07435 \\
.06571\end{array}$ & -.207 & .839 \\
\hline $\mathrm{MC}$ & $\begin{array}{l}\text { CG } \\
\text { EG }\end{array}$ & $\begin{array}{l}35 \\
35\end{array}$ & $\begin{array}{l}2.7502 \\
2.4617\end{array}$ & $\begin{array}{l}.55449 \\
.49186\end{array}$ & $\begin{array}{l}.08996 \\
.07877\end{array}$ & 2.416 & .017 \\
\hline
\end{tabular}


Note. 1: DC: discourse competence, OC: organizing a coherent conversation, MC: maintaining the conversation

Note. 2: p-value $<0.05=$ significant, $p$-value $>.05=$ not significant

Similarly, Table 4.2 indicates the overall results of the difference in the proficiency of the sub-skills of discourse competence. The table shows that p-values for "organizing a coherent conversation" are .839 which is greater than the p-value of 0.05 . Hence, the difference in proficiency regarding sub-skill "organizing a coherent conversation" is not significant at 0.05 between the comparison and treatment groups. The table, however, shows that P-value for sub-skill "maintaining conversation" is .017 , which is smaller than the p-value 0.05 , thereby confirming that the difference in proficiency concerning sub-skill "maintaining conversation" was significant at 0.05 . Moreover, the mean scores of the aforementioned speaking sub-skill indicate that the difference is significant in favor of the control group.

Table 4. 3 T-test Results of the CG and EG regarding their Mean Scores in Overall DC on the

Post-test

\begin{tabular}{|c|c|c|c|c|c|c|}
\hline Groups & $\mathrm{N}$ & $\mathrm{M}$ & SD & ST.Error. M & T-value & P-Value \\
\hline Control & 35 & 19.8948 & 4.36533 & .70814 & 2514 & 013 \\
\hline Experimental & 35 & 22.5001 & 4.70860 & .75397 & & \\
\hline
\end{tabular}

Note. 1: DC: discourse competence

Note. 2: p-value $<0.05=$ significant, $\mathrm{p}$-value $>0.05=$ not significant

The p-value .013 as shown in Table 4.3 above, is smaller than the p-value 0.05 , which shows that the variance was significant regarding improvement in the overall discourse competence between the students of the groups at p-value 0.05. The mean scores of both the groups; however communicate that the improvement level in the entire discourse competence was significant in support of the treatment group, which suggests that the text of poetry was better suited than the texts of grammar for developing and improving the overall discourse competence of the students. Thus, the table verifies the alternative hypothesis which states that the difference between the mean scores of the treatment group taught through poetry and the comparison group taught through the texts of grammar on the post-test in general speaking proficiency will be significant in favor of the treatment group. Thus, the alternative hypothesis stating that the text of poetry has a substantial effect on the entire grammatical competence of the students.

Table 4.4 T-tests Results of CG and EG in the Sub-skills of DC on the Post-test

\begin{tabular}{llllllll}
\hline Sub-skills of DC & Groups & $\mathrm{N}$ & $\mathrm{M}$ & $\mathrm{SD}$ & ST. Error. M & T-Value & P-Value \\
\hline OC & CG & 35 & 2.5656 & .83964 & .13620 & -3.058 & \multirow{2}{*}{.004} \\
& EG & 35 & 2.8075 & .72197 & .11560 & & \\
MC & CG & 35 & 3.3420 & .62714 & .10173 & -2.301 & .023 \\
& EG & 35 & 3.8332 & .7722 & .12366 & &
\end{tabular}

Note.1: DC: discourse competence, OC: organizing a coherent conversation, MC: maintaining the conversation

Note. 2: $\mathrm{p}$-value $<0.05=$ significant, $\mathrm{p}$-value $>0.05=$ not significant

Likewise, Table 4.4 presents the results of the proficiency of the sub-skills of discourse competence. The table indicates that the p-values for the sub-skills organizing coherent conversation and maintaining the conversation are .004 and .023 respectively, which are smaller than the p-value 0.05 showing that the difference in terms of improvement in the aforementioned sub-skills was significant at the p-value 0.05 . Moreover, the mean scores of the aforesaid sub-skills indicate that the difference was significant in support of the treatment group. Thus, the outcomes of the table above confirm the significant effect of the text of poetry on the development and improvement of proficiency in organizing coherent conversations and maintaining the conversation. Hence, the table endorses the alternative hypothesis which states that the difference between the mean scores of the treatment group and the comparison group on the post-test in sub-skills including 1) organizing coherent conversation and 2) maintaining the conversation will be significant in favor of the treatment group. Hence, the alternative hypothesis maintaining that the text of poetry has a significant effect on the sub-skills including 1) organizing coherent conversation and 2) maintaining the conversation.

\section{Discussion}

This study investigated the effect of traditional teaching materials and poems on the discourse competence of ESL learners. This quasi-experimental study had a comparison group and a treatment 
group. The students of the comparison group were taught through the texts of grammar whereas the text poetry was utilized in the treatment group. A speaking type of pre-tests and post-tests were conducted before and after the intervention. Moreover, observation field notes were employed to find out the reasons behind the performance of the students of both groups. The results indicated that the learners in the experimental group performed significantly better in the overall discourse competence in the post-test (see Table 4.1). Likewise, the students of the experimental also performed significantly better in the sub-skills of organizing a coherent conversation and maintaining the conversation. The observation field notes indicate that the students of the treatment group actively took part in the group activities as they could interpret the text of poetry in a variety of ways due to the ambiguity in the text of poetry (Faver 2008). Moreover, the subjective nature of poetry provided autonomy to the students of the experimental group to freely and frequently share their ideas. The text of poetry deals with human feelings and emotions (Khatib, 2011; Van 2009; Ghosn 2002; Lazar 1993). Hence, the learners in the experimental group found their feelings in the poems and expressed and shared their personal stories with their fellow learners. This increased their confidence level. Additionally, the cultural elements in the text of the poetry (Nasr 2001; Khansir 2000; Khatib 2011) enabled the students of the experimental group to develop an insight into certain expressions of the English language. Further, they juxtaposed their own culture with that of the target language which further increased their understanding of the target language.

Similarly, the verbal music and rhythmic pattern (Collins 2008; Any 2008) of the poems grew the students of the experimental group keen on reading the text aloud. They recited other relevant poems they remembered. Besides, they compared English poems with poems in their native languages. This practice gave them an insight into the poetic construction of English poetry. Poetry has authentic language as it is written primarily for native speakers. Moreover, the construction of sentences in poetry is different from the structure of the daily conversation (Khatib, 2011; Nasr, 2001). The students in the treatment group were therefore recurrently asked to convert the poetic structure of the sentences into the normal conversational structure. Hence, the learners would unfold and break the poetic structure into normal subject, verb, and object construction. This practice enhanced students' knowledge of the target language. Interaction in the target language is one of the vital elements of learning the language. Language texts shall be open to different interpretations thereby leading to interaction among the learners (Maley \& Duff, 1989; Carter \& Long, 1991; Nasr, 2001; Khatib \& Rahimi, 2012). The learners of the treatment group related the text of the poems to their social and practical lives. They felt encouraged to bring their social and personal experiences and stories to the classroom and freely share them with their fellow learners. They interpreted the poems in the light of their personal experiences and hence gave different interpretations to the poems. This triggered discussions and caused comprehensive interaction among the students of the treatment group.

On the contrary, the language learners in the comparison group were hesitant in expressing their opinions due to the objective nature of the texts. They could hardly relate the text to their personal and social lives. Moreover, traditional teaching materials rarely had cultural elements of the target language. Hence, the students of the control group could not interpret the text according to their own culture. Moreover, they did not participate actively in group activities as the traditional teaching materials could barely be exploited for group activities. Hence, this study proves that the text of poetry could be used in an ESL classroom for teaching discourse competence.

\section{Conclusion}

This research project was executed to investigate the impact of poems as language teaching materials on the discourse competence of English as a second language (ESL) learners. Discourse competence is a sub-skill of overall speaking skills. Discourse competence has been further subdivided into two sub-skills including 'organizing a coherent conversation and maintaining the conversation'. This quasi-experimental contained a comparison group and a treatment group. There were 35 students in each group, thus, 70 students in all. The respondents of this research study were from the faculty of social sciences, University of Malakand, Pakistan. Furthermore, the students were in their third semester and studied English as a minor course. Traditional teaching materials were utilized in the control group whereas poems were used to teach the students of the experimental group. A speaking kind of pre-tests and post-tests were conducted to determine the impact of both forms of teaching materials on the discourse competence of the students of CG and EG. Moreover, observation field 
notes were also employed to comprehend the impact of the teaching materials on the students' behavior inside their relevant classrooms. The statistical analysis of the scores on the tests showed that the students of EG performed significantly better on the post-test concerning organizing $a$ coherent conversation and maintaining the conversation. The observation field notes showed that the students of EG were more interactive inside the classroom. Moreover, they related the topics to their social, cultural, and personal lives. Additionally, they actively participated in group activities and acted as the main stakeholders of the learning process. On the contrary, the students of CG were found to be reluctant in speaking the target language. They did not wholeheartedly participate in group activities. The reasons for the better performance of the students of EG could be attributed to the cultural and linguistic richness, personal relevance, universality, and ambiguity in the text of poetry (Mittal 2016; Ainy, 2008; Lazar 1993; Duff \& Maley, 1990).

\section{References}

Ainy, S. (2008). "Poetry in the Language Classroom to Assist in the Development of Speaking Skill." ESL Journal. Available at: http://www. journal. org/289047413. HTML.

Ali, S., Khan, G. Z., \& Amin, I. (2019). Poetry Guided Speaking and Motivation in English as a Second Language Classroom. Pakistan Journal of Social Sciences (PJSS), 39(3): 879-886

Carter, R. A., \& M. N. Long (1991). Teaching literature, Addison-Wesley Longman Limited.

Collins, R. (2008). Using writing activities with young EFL learners. Proceedings from International Conference on ELT in Primary Education.

Dimitrov, D. M., \& P. D. Rumrill Jr (2003). "Pretest-posttest designs and measurement of change." Work 20(2): 159-165.

Duff, A. \& A. Maley (1991). Literature: a resource book for teachers, Oxford: Oxford University Press.

Faver, S. (2008). "Repeated reading of poetry can enhance reading fluency." The Reading Teacher 62(4): 350-352.

House, J. (1996). "Developing pragmatic fluency in English as a foreign language: Routines and metapragmatic awareness." Studies in second language acquisition 18(02): 225-252.

Khansir, A. A. (2012). "Teaching poetry in the ELT classroom." International review of social sciences and humanities 3(1): 241-245.

Khatib, M., \& A. H. Rahimi (2012). "Literature and language teaching." Journal of Academic and Applied Studies 2(6): 32-38.

Lazar, G. (1993). Literature and language teaching: A guide for teachers and trainers. Cambridge. Cambridge University Press.

Louwerse, M., \& Mitchel. H. (2003). "Towards Taxonomy of a Set of Discourse Markers in Dialogue: A Theoretical and Computational Linguistic Account". Discourse Processes," 35(3): 243-281.

Maley, A. \& Duff. A. (1989). The Inward Ear: Poetry in the Language Classroom, ERIC.

O’Brien, T. (1999). "A suggested model for teaching literature." Course Notes. Manchester: University of Manchester.

Raza, W. (2008). "Patterns of Pakistani English pronunciation and pedagogic priorities." Market Forces 4(3): 102-112.

Shamim, F. (2008). "Trends, issues, and challenges in English language education in Pakistan." Asia Pacific Journal of Education 28(3): 235-249.

Shamim, F. (2011). "English as the language for development in Pakistan: Issues, challenges, and possible solutions." Dreams and realities: Developing countries and the English language 14(1): 291-310.

Van, T. T. M. (2009). The Relevance of Literary Analysis to Teaching Literature in the EFL Classroom. In English Teaching Forum (Vol. 47, No. 3, p. 2). . English Teaching Forum, US Department of State. Bureau of Educational and Cultural Affairs, Office of English Language Programs, SA-5, 2200 C Street NW 4th Floor, Washington, DC 20037, ERIC.

Yoshida, R. (2003). "Evaluations of communicative competence in Japanese by learners and native speakers." ASAA e-Journal of Asian Linguistics and Language Teaching 4(4): 1-20.

Young, R. F. (2002). "13. Discourse Approaches to Oral Language Assessment." Annual Review of Applied Linguistics 22: 243-262 